\section{Pacific Northwest}

National Laboratory

Operated by Battelle for the

U.S. Department of Energy

\title{
Eddy Current Imaging of Machined Grooves on a Nickel Wave Strip
}

\author{
E. S. Andersen \\ R. A. Mathews \\ G. J. Sandness
}

January 2006

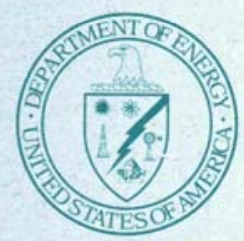




\section{DISCLAIMER}

This report was prepared as an account of work sponsored by an agency of the United States Government. Neither the United States Government nor any agency thereof, nor Battelle Memorial Institute, nor any of their employees, makes any warranty, express or implied, or assumes any legal liability or responsibility for the accuracy, completeness, or usefulness of any information, apparatus, product, or process disclosed, or represents that its use would not infringe privately owned rights. Reference herein to any specific commercial product, process, or service by trade name, trademark, manufacturer, or otherwise does not necessarily constitute or imply its endorsement, recommendation, or favoring by the United States Government or any agency thereof, or Battelle Memorial Institute. The views and opinions of authors expressed herein do not necessarily state or reflect those of the United States Government or any agency thereof.
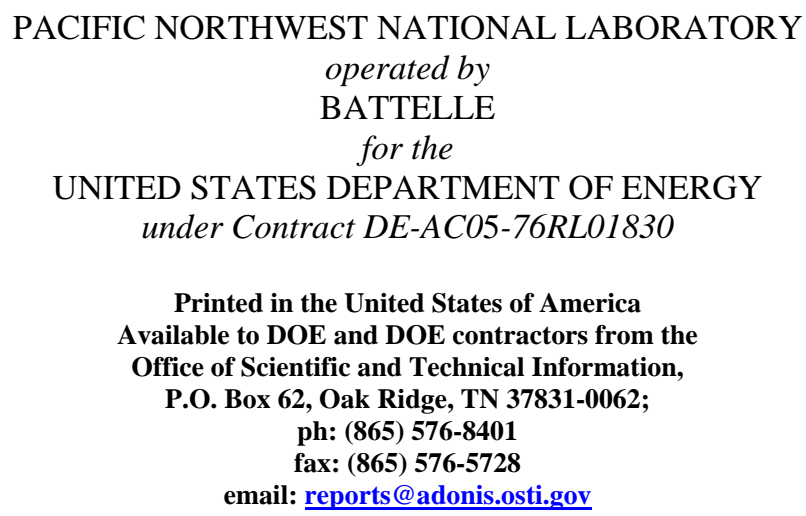

Available to the public from the National Technical Information Service, U.S. Department of Commerce, 5285 Port Royal Rd., Springfield, VA 22161 ph: (800) 553-6847 fax: (703) 605-6900

email: orders@ntis.fedworld.gov online ordering: http://www.ntis.gov/ordering.htm 
PNNL-15701

\section{Eddy Current Imaging of Machined} Grooves on a Nickel Wave Strip

E. S. Andersen

R. K. Mathews

G. J. Sandness

January 2006 
PNNL-15701

\section{Summary}

Eddy current measurements offer a means of rapidly detecting, imaging, and characterizing a variety of features on the surfaces of metallic objects. In this case, the target of interest was a set of machined grooves in a small strip of nickel sheet. A series of brief tests were performed using an automated $\mathrm{X}-\mathrm{Y}$ scanner and an available test probe to scan the test strip. Although the coil in the probe was too large to resolve individual grooves, the system successfully imaged the grooves, accurately determined the groove spacings along the length of the strip, and provided data from which the depths of the grooves could be calculated. Supplemental measurements made with an optical profilometer provided data needed to convert the eddy current voltages to groove depths.

These tests indicate that an operational eddy current system would be an effective means of inspecting nickel surfaces. Scans to detect surface topography such as the grooves on the test strip require only measurements of the lift-off response of the sensor and are not adversely affected by the ferromagnetic property of nickel. An operational system designed to detect and characterize features as small, or as closely spaced, as the grooves on the test strip should include smaller sensors than those used in our tests. Much smaller coils than our .060-in.diameter coil are available or can be fabricated. Solid-state magnetoresistive sensors are an alternative to coils and are available in very small sizes. Numerical modeling offers an efficient means of evaluating alternate sensor configurations and the performance of sensors in specific applications. Modeling, hardware tests, and the development of calibration standards would be important facets of an effort to develop an eddy current inspection system for the type of application discussed in this report. 


\section{Contents}

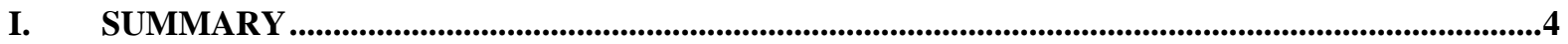

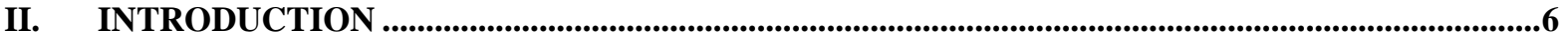

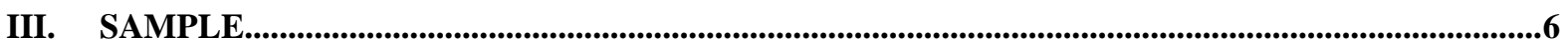

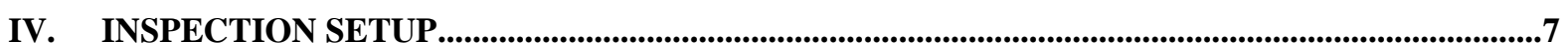

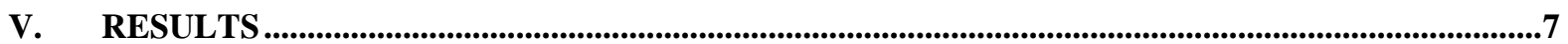

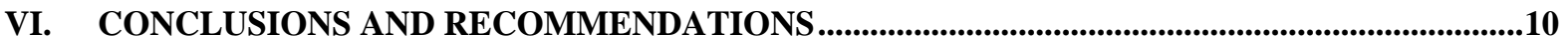


PNNL-15701

\section{Introduction}

Pacific Northwest National Laboratory (PNNL) evaluated the ability of an automated eddy current (EC) inspection method to determine the spacing and depth of a set of grooves machined in the top surface of a small strip of nickel. Because nickel is an electrically conductive ferromagnetic material, a high-frequency magnetic field produced at its surface is strongly attenuated as it propagates into the body of the material. Thus, EC inspections to detect flaws or other features in nickel objects may be hampered by limited penetration depth and the occurrence of spurious anomalies related to variations in magnetic permeability. Recent work at PNNL has addressed these issues as part of a successful effort to inspect nickel platings on the inner and outer surfaces of Zircaloy tubing. In comparison, the current task of resolving and measuring closely spaced grooves on the surface of a nickel plate is, in principle, relatively simple. Scanning with a coil-type eddy current sensor held at a fixed height just above the grooved surface will produce a response due to lift-off (the height of the coil above the metal surface) that will define the topography of the surface. The more difficult aspect of this approach is related to geometry - to ensure that individual grooves can be resolved, the diameter of the probe coil should not be much greater than the groove spacing. Special measures may be needed to produce sensors small enough to resolve grooves that are spaced more closely than those present on the test strip provided for this evaluation.

The objective of this exploratory inspection was to use available EC probes to:

- image the surface

- estimate the spatial resolution provided by the best available probe

- measure the distance between the peaks on the machined surface

- evaluate the ability of the system to measure the depths of the grooves.

\section{Sample}

The provided sample was a small strip of nickel with arc-shaped machining marks on the surface (wave strip). It was approximately $7.2 \mathrm{~cm}$ (2.85 in.) long, $0.78 \mathrm{~cm}$ (0.31 in.) wide, and appeared to be approximately $0.36 \mathrm{~mm}$ (.013 in.) thick. It was mounted on a glass block as shown in Figure 1. 


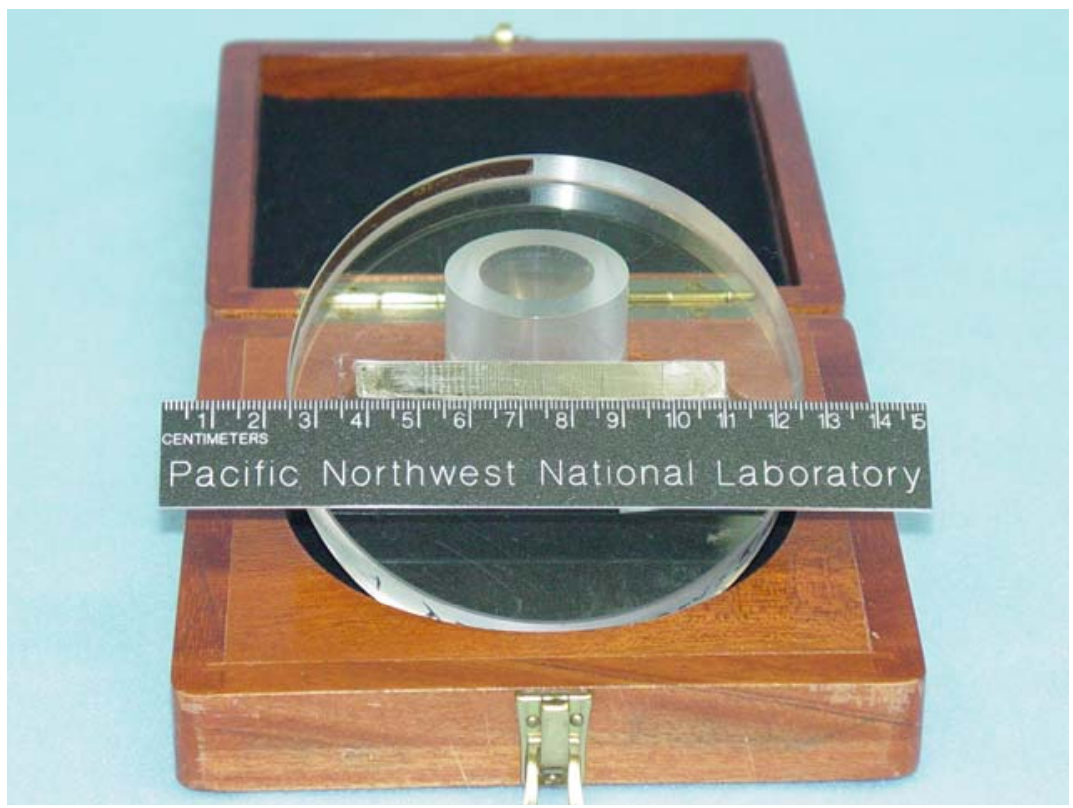

Figure 1. Nickel wave strip sample.

\section{Inspection Setup}

An initial series of tests were performed involving several sensors, or probes, to determine the optimum probe type and frequency to use for the inspection. Two probes types were represented. The first utilized a simple pancake coil oriented with its axis perpendicular to the test surface. The second, a plus-point probe type, utilized two orthogonal coils with axes parallel to the test surface. All of these probes had relatively small-diameter coils, an important factor in maximizing spatial resolution. The probe selected for a more detailed inspection of the nickel sample contained a 0.06-in.-diameter pancake coil.

A Zetec Model MIZ-27 eddy current instrument was used to perform all of the EC measurements made in this brief exploratory task. The instrument was coupled to an automated eddy current inspection system. The sample was mounted on a platform under a computer-controlled $\mathrm{X}-\mathrm{Y}-\mathrm{Z}$ translation bridge, that was used to execute raster scans of the probe on the sample. A scan spacing of approximately half the diameter of the probe coil provided approximately 12 scans across the width of the test strip. The data spacing along the length of the test strip (the X-coordinate) was approximately 0.0007 inches.

\section{Results}

After scanning the sample at several frequencies between $1 \mathrm{MHz}$ and $5 \mathrm{MHz}$, we found that an operating frequency of $1.2 \mathrm{MHz}$ provided the best results in terms of spatial resolution. (The optimal frequency would almost certainly be different if a different probe were used.) Figure 2 is an image of the nickel surface as represented by the magnitude of the eddy current signal. The uneven background color is thought to be the result of variation in the vertical distance between the probe face and surface of the test strip. The grooves in this 
image have a somewhat jagged appearance because the probe translation over the sample exhibited a small offset in the $\mathrm{x}$ coordinate as it scanned from right to left, then left to right. The individual grooves are more clearly shown in Figures 3 and 4.

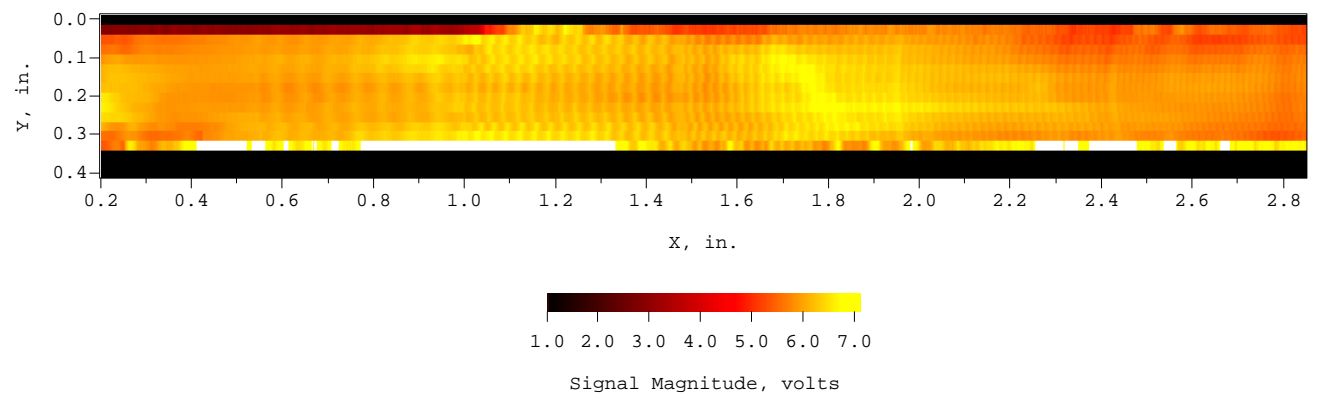

Figure 2. EC image of the grooved surface of the nickel sample.

Figure 3 is a profile of the magnitude of the EC signal from a single scan along the length of the sample. With an appropriate scale factor, it would represent the measured profile of the grooved surface. Figure 4 is a two-dimensional image of the same data.

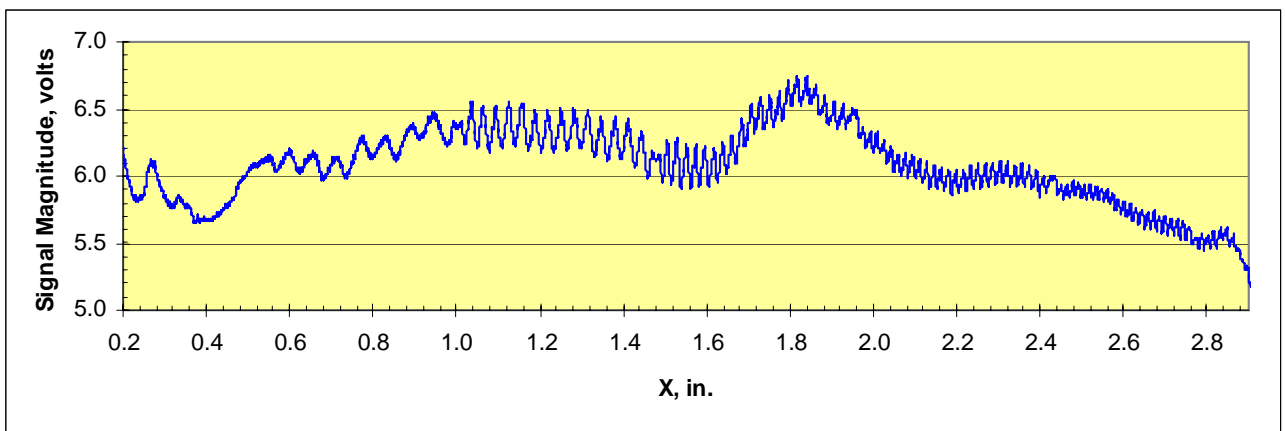

Figure 3. EC magnitude profile.
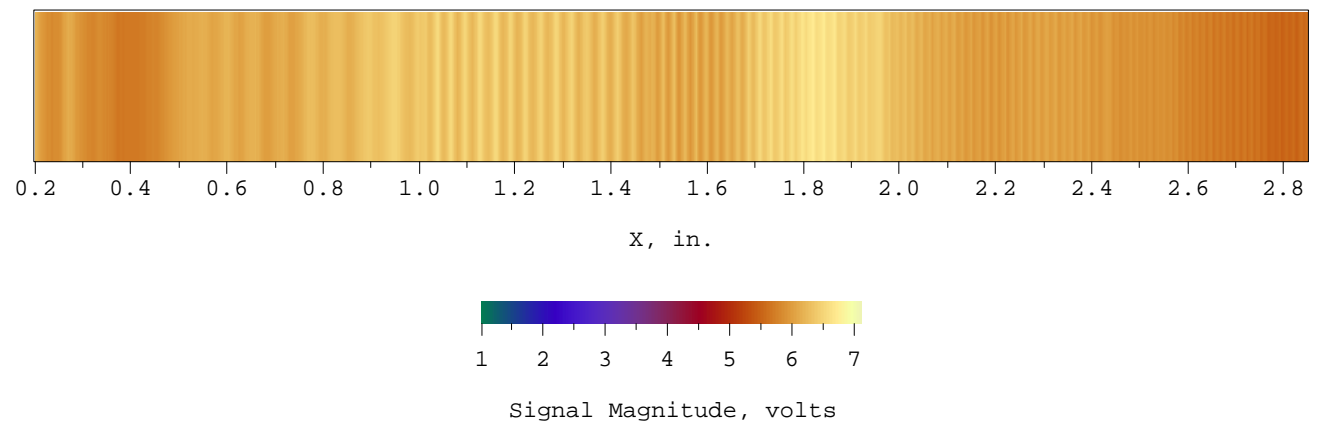

Figure 4. 2D image of data from a single scan.

For the most part, the measured quantity in this test was an average EC lift-off response with an added periodic component as the grooves moved past the probe coil. That periodic response provided a decent dimensional representation of the groove spacing. Based on the profilometer measurements, the maximum error in the EC-measured groove spacing was approximately $4 \%$. Although assigning a value to the spatial resolution associated with these EC measurements is not straightforward, an estimate of one-half the diameter of the coil (i.e, 
approximately 0.30 in.) is not inconsistent with the data. Determining the depths of the grooves requires calibration data. The necessary data was obtained by making a supplemental scan of the sample using a Veeco Model NT2000 optical profilometer. This instrument provided quantitative measurements of groove depth along the length of the sample. An example of the profilometer data is shown in Figure 5. Ideally, converting the peak-valley voltage to groove depth should require only a constant scale factor. In this case, as shown in Figure 6, the scale factor is a function of the groove spacing. This is a consequence of the interaction of the probe's relatively large magnetic field with an increasing number of grooves as the probe is moved along the length of the sample. The use of a smaller probe coil would reduce this effect.

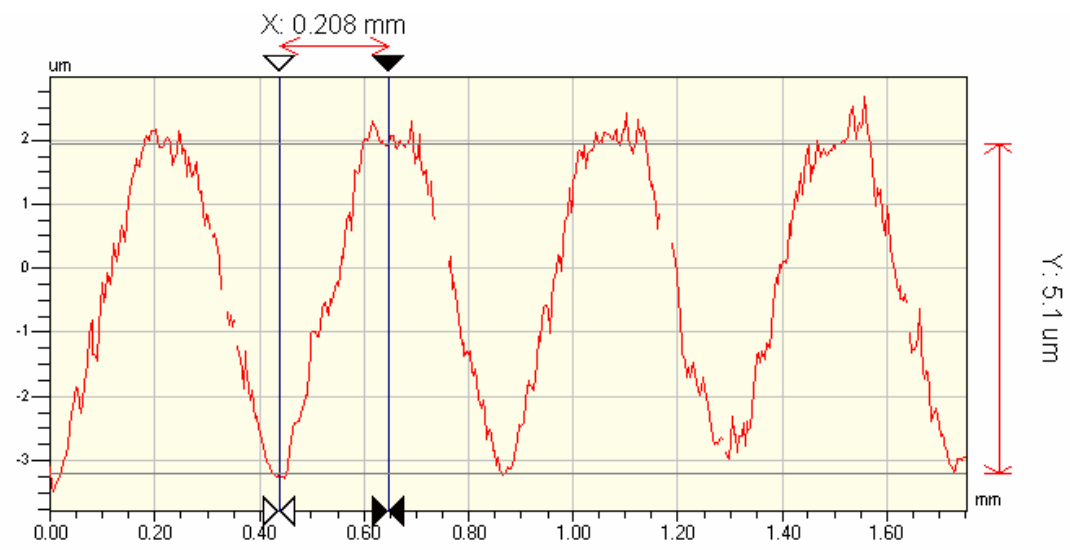

Figure 5. Profilometer scan of grooves near the center of the sample.

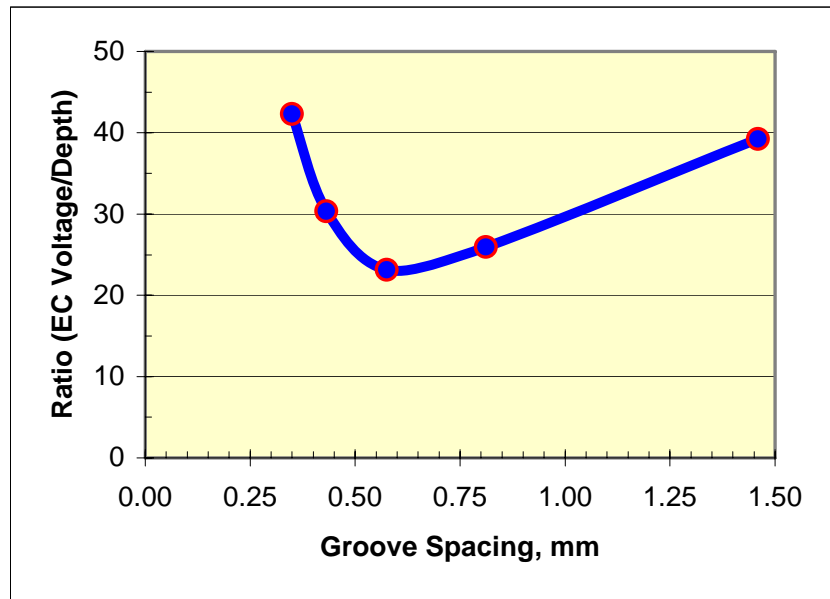

Figure 6. Scale factor for voltage-to-depth conversion. 
The results discussed above are summarized in the following table:

$\begin{array}{ccccc}\text { Sample } & \begin{array}{c}\text { Spacing } \\ \text { Section }\end{array} & \begin{array}{c}\text { Groove } \\ \text { Depth } \\ (\mu \mathrm{m})\end{array} & \begin{array}{c}\text { EC } \\ \text { Voltage }\end{array} & \begin{array}{c}\text { Ratio -- } \\ \text { Depth/ } \\ \text { Voltage }\end{array} \\ 1 & 1.459 & 5.3 & 0.135 & 39.26 \\ 2 & 0.812 & 4.9 & 0.189 & 25.93 \\ 3 & 0.575 & 5.3 & 0.229 & 23.14 \\ 4 & 0.431 & 5.1 & 0.168 & 30.36 \\ 5 & 0.350 & 5.5 & 0.130 & 42.31\end{array}$

\section{Conclusions and Recommendations}

The simple inspection technique described above proved to be capable of imaging the grooves in the nickel test piece. Also, comparisons with measurements by an optical profilometer showed that it was able to measure the spacing of the grooves with a maximum error of $4 \%$. Because the size of the best available probe coil was larger than the groove spacing over a major part of the test strip, much of the data represented the response of the coil averaged over several grooves. The apparent effect of this was not great in this case, even though the calibration curve needed to calculate groove depth was a function of groove spacing. If there is a continuing need to measure and characterize features similar to the grooves machined onto the surface of the test strip, an effort should be made to develop or acquire a probe with a much smaller coil or with a very small solid-state sensor. This, in turn, will probably require an effort to ensure that the height of the sensor above the surface of the test piece can be held constant. Ultimately, the accuracy and reliability of eddy currents inspections depend on the availability of good standards. A standard with known properties and inspection characteristics greatly enhances the probability of developing a robust inspection technique. A virtue of an eddy current inspection method is that it is exceptional at detecting change. The challenge is to quantify that change. If the material properties of either the standard or the part being inspected are not known to be stable, or constant, eddy current methods become difficult to apply in a quantitative way.

Based on testing to date, several additional activities are recommended to enhance the capabilities of the eddy current imaging technique. These areas are suggested as a means to improve the results of the testing:

1) Clarify the objectives and expected outcomes for the inspection.

2) Establish a robust set of functions and requirements for the inspection system.

3) Model the eddy current technique to optimize probe selection and inspection development, focusing on
a. probe coil diameter
b. probe drive frequency
c. spatial resolution
d. depth measurement
e. material properties 
4) Acquire or develop an EC sensor with dimensions consistent with those of the features to be detected, imaged, measured, and characterized.

5) Prepare/obtain test samples.

6) Inspect test samples using parameters derived from numerical modeling.

7) Identify problem areas and establish recommendations for mitigating those problems.

8) Modify the inspection setup and retest.

9) Formalize the results.

A prototype inspection system could be built based on the success of this preliminary testing. 
PNNL-15701

Distribution List 